03,19

\title{
Тепловое расширение ограниченных полупроводниковых твердых растворов $\mathrm{Ag}_{x} \mathrm{~Pb}_{1-x} \mathrm{~S}$
}

\author{
() С.И. Садовников
}

Институт химии твердого тела УрО РАН,

Екатеринбург, Россия

E-mail: sadovnikov@ihim.uran.ru

Поступила в Редакцию 2 июля 2018 г.

В окончательной редакции 21 декабря 2018 г.

Принята к публикации 27 декабря 2018 г.

\begin{abstract}
Методом химического соосаждения из водных растворов ацетата свинца и нитрата серебра в присутствии сульфидизатора, комплексообразующих и стабилизирующих агентов синтезированы однофазные порошки кубических твердых растворов $\mathrm{Ag}_{x} \mathrm{~Pb}_{1-x} \mathrm{~S}$ с максимальным относительным содержанием серебра до $x=0.12$. Методом дилатометрии в области температур $295-580 \mathrm{~K}$ впервые измерено тепловое расширение синтезированных полупроводниковых твердых растворов $\mathrm{Ag}_{x} \mathrm{~Pb}_{1-x} \mathrm{~S}$. Показано, что замещение атомов свинца атомами серебра в $\mathrm{Ag}_{x} \mathrm{~Pb}_{1-x} \mathrm{~S}$ приводит к небольшому понижению коэффициента термического расширения, связанному с изменением ангармонизма атомных колебаний.
\end{abstract}

Исследование выполнено при финансовой поддержке Российского научного фонда (проект № 17-73-10104) в ИХТТ УрО РАН.

DOI: 10.21883/FTT.2019.06.47679.182

\section{1. Введение}

В последние годы вырос интерес к сульфидным твердым растворам, расширяющим возможность модификации решеточных и электронных свойств сульфидов. Сульфиды свинца и серебра $\mathrm{PbS}$ и $\mathrm{Ag}_{2} \mathrm{~S}$ - одни из наиболее востребованных полупроводников, однако сведения об их твердых растворах $\mathrm{Ag}_{x} \mathrm{~Pb}_{1-x} \mathrm{~S}$ крайне ограничены.

В нормальных условиях крупнокристаллический (bulk) сульфид свинца является прямым узкозонным полупроводником с кубической (пр.гр. $F m \overline{3} m$ ) структурой $B 1$. При температуре $300 \mathrm{~K}$ ширина запрещенной зоны $E_{g}$ монокристаллического сульфида свинца и поликристаллических пленок $\mathrm{PbS}$ равна $0.41-0.42 \mathrm{eV}[1,2]$. Сульфид свинца $\mathrm{PbS}$ применяется в таких устройствах как фотодетекторы с широким (от инфракрасного до ультрафиолетового) диапазоном излучения, солнечные элементы с высоким коэффициентом полезного действия, термоэлектрические преобразователи, оптические переключатели [3]. Крупнокристаллический сульфид серебра с моноклинной (пр.гр. $\left.P 2_{1} / c\right)$ структурой акантита $\alpha-\mathrm{Ag}_{2} \mathrm{~S}$ является прямым полупроводником с шириной запрещенной зоны около $\sim 0.9 \mathrm{eV}[4,5]$. Сульфид серебра $\mathrm{Ag}_{2} \mathrm{~S}$ широко используется как материал для электронных и сенсорных устройств [6,7]. В работе [8] показано, что получение композиционного материала $\mathrm{Ag}_{x} \mathrm{~Pb}_{1-x} \mathrm{~S}$ на основе твердых растворов узкозонного $\mathrm{PbS}$ и широкозонного $\mathrm{Ag}_{2} \mathrm{~S}$ позволяет добиться пошагового изменения ширины запрещенной зоны и регулирования сенсорной чувствительности твердых растворов к оксидам азота.

Сульфиды и сульфидные твердые растворы чаще всего используются в виде пленок на подложках, поэтому для их применения при повышенной температуре нужны данные о термическом расширении.

Согласно [9], коэффициент термического расширения поликристаллического $\mathrm{PbS}$ при температуре $300 \mathrm{~K}$ составляет $(19-20) \cdot 10^{-6} \mathrm{~K}^{-1}$, а по данным [10] равен $29.8 \cdot 10^{-6} \mathrm{~K}^{-1}$.

Коэффициент термического расширения пленки $\mathrm{PbS}$ измеряли в работах $[11,12]$. Согласно [11], при охлаждении пленки $\mathrm{PbS}$ от 423 до $293 \mathrm{~K}$ период кристаллической решетки a уменьшился от 0.59637 до $0.59326 \mathrm{~nm}$, и такому изменению периода соответствует коэффициент термического расширения $\alpha(423 \mathrm{~K})$, равный $\sim 40 \cdot 10^{-6} \mathrm{~K}^{-1}$. При повторном нагреве пленки $\mathrm{PbS}$ от 293 до $393 \mathrm{~K}$ период решетки увеличился, чему соответствовал коэффициент $\alpha(393 \mathrm{~K})$ около $\sim 28 \cdot 10^{-6} \mathrm{~K}^{-1}$. Согласно in situ исследованию теплового расширения пленок $\mathrm{PbS}$ при температуре до $473 \mathrm{~K}$ [12], коэффициент термического расширения составил $(37-39) \cdot 10^{-6} \mathrm{~K}^{-1}$ и близок к величине $\alpha$, определенной в работе [11].

Согласно [13], коэффициент линейного термического расширения крупнокристаллического акантита $\alpha-\mathrm{Ag}_{2} \mathrm{~S}$ равен $\sim 20 \cdot 10^{-6} \mathrm{~K}^{-1}$. Недавно тепловое расширение крупнокристаллического и нанокристаллического порошков сульфида серебра изучили в работах [14-16], согласно которым изотропный линейный коэффициент термического расширения нанокристаллического акантита $\alpha-\mathrm{Ag}_{2} \mathrm{~S}$ в области температур $\sim 300-400 \mathrm{~K}$ равен $(22-24) \cdot 10^{-6} \mathrm{~K}^{-1}$ и примерно в $1.2-1.3$ раза больше, чем $\alpha_{\text {ac }}$ крупнокристаллического акантита.

Из-за различия кристаллических структур сульфиды $\mathrm{PbS}$ и $\mathrm{Ag}_{2} \mathrm{~S}$ имеют ограниченную взаимную растворимость. Согласно [17], предельная растворимость крупнокристаллического $\mathrm{Ag}_{2} \mathrm{~S}$ в $\mathrm{PbS}$ достигается при $970 \mathrm{~K}$ и не 
превышает 0.4 mol.\%. Авторы [8] сумели получить пленки твердых растворов $\mathrm{Ag}_{x} \mathrm{~Pb}_{1-x} \mathrm{~S}$, в которых величина $x$ изменялась от 0 до 0.16. По сравнению с данными [17], твердые растворы с $x>0.08$ были пересышенными.

Никаких сведений о тепловом расширении твердых растворов $\mathrm{Ag}_{x} \mathrm{~Pb}_{1-x} \mathrm{~S}$ в литературе нет. В связи с этим целью настоящей работы является изучение теплового расширения твердых растворов сульфидов свинца и серебра и определение их коэффициента термического расширения.

\section{2. Образцы и экспериментальные методы}

Тонкодисперсные порошки сульфидов $\mathrm{PbS}$ и $\mathrm{Ag}_{2} \mathrm{~S}$ и сульфидных твердых растворов $\mathrm{Ag}_{x} \mathrm{~Pb}_{1-x} \mathrm{~S}$ синтезировали методом химического осаждения из водных растворов ацетата свинца $\mathrm{Pb}\left(\mathrm{CH}_{3} \mathrm{COO}\right)_{2}$, нитрата сеpeбра $\mathrm{AgNO} 3$, цитрата натрия $\mathrm{Na}_{3} \mathrm{C}_{6} \mathrm{H}_{5} \mathrm{O}_{7}$, гидроксида аммония $\mathrm{NH}_{4} \mathrm{OH}$ и тиокарбамида $\left(\mathrm{NH}_{2}\right)_{2} \mathrm{CS}$ по ранее предложенной методике [8]. Во всех реакционных смесях концентрация $\mathrm{NH}_{4} \mathrm{OH}$ составляла $4 \mathrm{~mol} \cdot \mathrm{l}^{-1}$, концентрации тиокарбамида и цитрата натрия были одинаковы и равны $0.05 \mathrm{~mol} \cdot \mathrm{1}^{-1}$. Концентрации ацетата свинца и нитрата серебра меняли в интервалах 0.01-0.05 и $0.001-0.015 \mathrm{~mol} \cdot 1^{-1}$ соответственно. При осаждении тиокарбамид как источник ионов серы являлся сульфидизатором. Попытка использовать сульфид натрия $\mathrm{Na}_{2} \mathrm{~S}$ как сульфидизатор оказалась неудачной вследствие почти мгновенного осаждения сульфида серебра вместо сульфидного твердого раствора $\mathrm{Ag}_{x} \mathrm{~Pb}_{1-x} \mathrm{~S}$. Использование тиокарбамида позволило снизить скорость осаждения сульфида серебра благодаря образованию комплексов $\left[\mathrm{Ag}\left(\mathrm{N}_{2} \mathrm{H}_{4} \mathrm{CS}\right)_{3}\right]^{+}$. Комплексообразующим агентом, препятствующим быстрому осаждению сульфида свинца, был цитрат натрия.

Осаждение проводили в щелочной среде при температуре $298 \mathrm{~K}$ и $p \mathrm{H}$ от 10 до 11 в течение $3 \mathrm{~h}$. Продолжительность нахождения полученного осадка в растворах составляла $2 \mathrm{~h}$. Осажденные порошки промывали дистиллированной водой методом декантации, фильтровали и сушили на воздухе при температуре $323 \mathrm{~K}$.

Bce осажденные порошки исследовали методом рентгеновской дифракции на дифрактометре Shimadzu $\mathrm{XRD}-7000$ в $\mathrm{Cu} K \alpha_{1,2}$-излучении. Рентгеновские измерения проводили в интервале углов $2 \theta=20-85^{\circ}$ с шагом $\Delta(2 \theta)=0.02^{\circ}$ и временем сканирования $10 \mathrm{~s}$ в точке. Рентгенограммы численно анализировали с помощью программного пакета X'Pert HighScore Plus [18].

Микроструктуру и элементный состав порошков твердых растворов $\mathrm{Ag}_{x} \mathrm{~Pb}_{1-x} \mathrm{~S}$ изучали методом сканирующей электронной микроскопии (СЭМ) на микроскопе JEOL-JSM LA 6390 с энерго-дисперсионным рентгеновским анализатором JED 2300 Energy Dispersive X-ray Analyzer.

Коэффициент термического расширения измеряли на цилиндрических образцах диаметром $5 \mathrm{~mm}$, спрессо- ванных под давлением $\sim 260 \mathrm{MPa} \mathrm{и} \mathrm{спеченных} \mathrm{в} \mathrm{ва-}$ кууме при температуре $\sim 470 \mathrm{~K}$ из синтезированных отожженных порошков однофазных твердых растворов

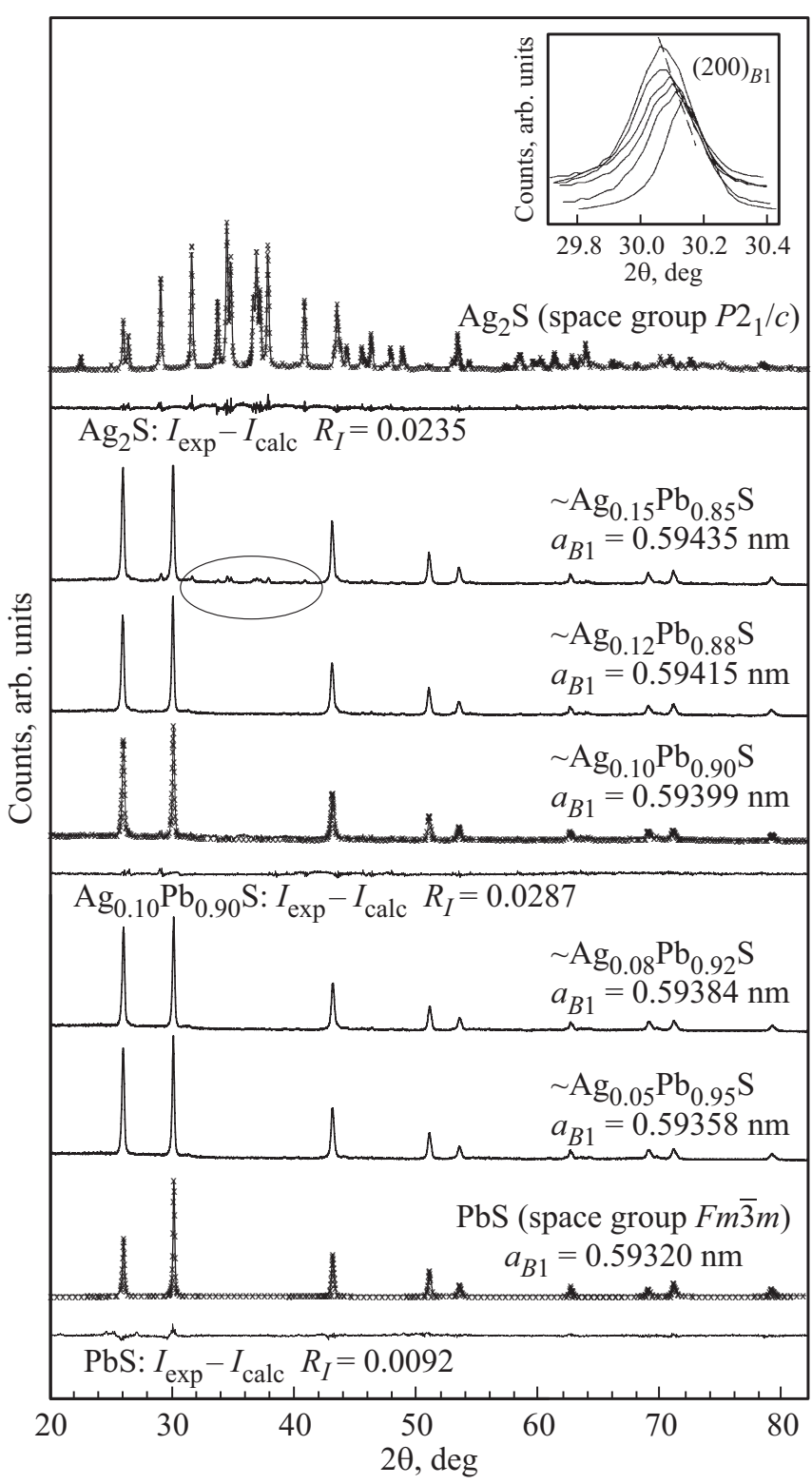

Рис. 1. Рентгенограммы сульфидов $\mathrm{Ag}_{2} \mathrm{~S}$ и $\mathrm{PbS}$ и ограниченных сульфидных твердых растворов $\mathrm{Ag}_{x} \mathrm{~Pb}_{1-x} \mathrm{~S}(x<0.15)$. Твердые растворы с $0.05 \leq x \leq 0.12$ имеют кубическую (пр.гр. $F m \overline{3} m)$ структуру и являются однофазными. Твердый раствор $\mathrm{Ag}_{0.15} \mathrm{~Pb}_{0.85} \mathrm{~S}$ наряду с основной кубической фазой содержит до 4-5wt.\% моноклинного (пр. гр. $P 2_{1} / c$ ) сульфида серебра $\mathrm{Ag}_{2} \mathrm{~S}$, чьи отражения на рентгенограмме выделены овалом. На вставке показано смещение отражения $(200)_{B 1}$ твердых растворов $\mathrm{Ag}_{x} \mathrm{~Pb}_{1-x} \mathrm{~S}$ в область меньших углов $2 \theta$ при замещении атомов $\mathrm{Pb}$ атомами $\mathrm{Ag}$ (при увеличении $x$ от 0 до 0.15). Для образцов $\mathrm{Ag}_{2} \mathrm{~S}, \mathrm{PbS}$ и $\mathrm{Ag}_{0.10} \mathrm{~Pb}_{0.90} \mathrm{~S}$ как пример минимизации дополнительно показаны расчетные рентгенограммы и разности $\left(I_{\text {exp }}-I_{\text {calc }}\right)$ между экспериментальными и рассчитанными рентгенограммами, а также приведены факторы Ритвелда $R_{I}$. Периоды твердых растворов $\mathrm{Ag}_{x} \mathrm{~Pb}_{1-x} \mathrm{~S}$ определены с точностью $\pm 0.00005 \mathrm{~nm}$. 
Экспериментальны5е соотношения интенсивностей $I_{111} / I_{200}$ отражений $(111)_{B 1}$ и $(200)_{B 1}$

\begin{tabular}{c|c|c|c|c|c|c}
\hline Состав & $\mathrm{PbS}$ & $\mathrm{Ag}_{0.05} \mathrm{~Pb}_{0.95} \mathrm{~S}$ & $\mathrm{Ag}_{0.08} \mathrm{~Pb}_{0.92} \mathrm{~S}$ & $\mathrm{Ag}_{0.10} \mathrm{~Pb}_{0.90} \mathrm{~S}$ & $\mathrm{Ag}_{0.12} \mathrm{~Pb}_{0.88} \mathrm{~S}$ & $\mathrm{Ag}_{0.15} \mathrm{~Pb}_{0.85} \mathrm{~S}$ \\
\hline$I_{111} / I_{200}$ & 0.62 & 1.12 & 1.14 & 1.15 & 1.16 & 1.17
\end{tabular}

$\mathrm{Ag}_{x} \mathrm{~Pb}_{1-x} \mathrm{~S}$. Длина образцов составляла $\sim 4-6 \mathrm{~mm}$. Перед прессованием порошки предварительно отжигали в вакууме $0.013 \mathrm{~Pa}\left(10^{-4} \mathrm{~mm} \mathrm{Hg}\right)$ при медленном двухчасовом нагреве со скоростью $0.5 \mathrm{~K} \cdot \mathrm{min}^{-1}$ до $393 \mathrm{~K}$ и последующем вакуумном отжиге при $393 \mathrm{~K}$ в течение $2 \mathrm{~h}$.

Измерения проводили на дилатометре NETZSCH DIL 402С в атмосфере гелия Не при давлении $1.01 \cdot 10^{5} \mathrm{~Pa}$ и изменении температуры от 293 до $573 \mathrm{~K}$ с шагом $0.5 \mathrm{~K}$. Скорость нагрева составляла $4 \mathrm{~K}_{\text {мин }}{ }^{-1}$.

\section{3. Влияние состава на тепловое расширение твердых растворов $\mathrm{Ag}_{x} \mathrm{~Pb}_{1-x} \mathrm{~S}$}

Согласно данным сканирующей электронной микроскопии, средний размер частиц в осажденных порошках $\mathrm{Ag}_{x} \mathrm{~Pb}_{1-x} \mathrm{~S}$ составляет $\sim 300-500 \mathrm{~nm}$, а в порошках $\mathrm{PbS}$ и $\mathrm{Ag}_{2} \mathrm{~S}-\sim 100$ и $\sim 800 \mathrm{~nm}$ соответственно.

Рентгенограммы синтезированных порошков $\mathrm{PbS}$, $\mathrm{Ag}_{2} \mathrm{~S}$ и твердых растворов $\mathrm{Ag}_{x} \mathrm{~Pb}_{1-x} \mathrm{~S}$ представлены на рис. 1. Количественный анализ рентгенограммы сульфида серебра и сравнение с данными [19] показывает, что наблюдаемый набор дифракционных отражений соответствует моноклинному (пр.гр. $P 2_{1} / c$ ) акантита $\alpha-\mathrm{Ag}_{2} \mathrm{~S}$. Порошок сульфида свинца $\mathrm{PbS}$ имеет кубическую (пр. гр. $F m \overline{3} m)$ структуру с периодом элементарной ячейки $0.5932 \mathrm{~nm}$. Судя по рентгенограммам, твердые растворы $\mathrm{Ag}_{x} \mathrm{~Pb}_{1-x} \mathrm{~S}$ с $x \leq 0.12$ тоже являются кубическими и однофазными, тогда как твердый раствор $\mathrm{Ag}_{0.15} \mathrm{~Pb}_{0.85} \mathrm{~S}$ является двухфазным и наряду с основной кубической фазой содержит до 4-5 wt.\% моноклинного сульфида серебра. Об образовании твердых растворов свидетельствуют постепенное изменение соотношения интенсивностей отражений $(111)_{B 1}$ и $(200)_{B 1}$ (таблица) и смещение всех отражений в область меньших углов $2 \theta$ (рис. 1, вставка), т.е. небольшое увеличение периода $a_{B 1}$ кубической решетки от 0.59320 до $0.59435 \mathrm{~nm}$ при замещении свинца серебром. Для образцов $\mathrm{A}_{2} \mathrm{~S}$, $\mathrm{PbS}$ и $\mathrm{Ag}_{0.10} \mathrm{~Pb}_{0.90} \mathrm{~S}$ как пример минимизации дополнительно показаны расчетные рентгенограммы и разности $\left(I_{\text {exp }}-I_{\text {calc }}\right)$ между экспериментальными и рассчитанными рентгенограммами. Малая величина факторов Ритвелда $R_{I}$ подтверждает высокую точность выполненного полнопрофильного анализа.

Количественный анализ рентгенограмм ограниченных твердых растворов $\mathrm{Ag}_{x} \mathrm{~Pb}_{1-x} \mathrm{~S}$, выполненный с использованием программного обеспечения [18], подтвердил, что наблюдаемое увеличение периода $a_{B 1}$ кубической решетки обусловлено замещением атомов $\mathrm{Pb}$ атомами $\mathrm{Ag}$. Согласно [20], радиусы иона свинца $\mathrm{Pb}^{2+}$ и иона серебра
$\mathrm{Ag}^{+}$составляют $0.120 \mathrm{~nm}$ и $0.126 \mathrm{~nm}$ соответственно. Количественный анализ рентгенограмм позволил также оценить величину $x$, т.е. относительное содержание серебра в металлической подрешетке, с точностью \pm 0.015.

Для оценки относительного содержания серебра и свинца было использовано также изменение периода решетки твердых растворов $\mathrm{Ag}_{x} \mathrm{~Pb}_{1-x} \mathrm{~S}$. Ограниченные твердые растворы замещения $\mathrm{Ag}_{x} \mathrm{~Pb}_{1-x} \mathrm{~S}$ сохраняют кубическую структуру сульфида $\mathrm{PbS}$, поэтому можно принять, что решетка сульфида серебра в области ограниченной растворимости искажается до кубической. Согласно [14,15], объем элементарной ячейки моноклинного сульфида серебра при $273 \mathrm{~K}$ равен $0.2260 \mathrm{~nm}^{3}$, поэтому период модельной кубической элементарной ячейки с этим же объемом равен $a_{\mathrm{Ag}_{2} \mathrm{~S}}^{*}=0.6091 \mathrm{~nm}$. Если в первом приближении период кубической решетки $a_{\mathrm{ss}}$ твердого раствора при замещении свинца серебром меняется линейно по правилу Вегарда, то используя значения $a_{\mathrm{PbS}}=0.5932 \mathrm{~nm}$ и $a_{\mathrm{Ag}_{2} \mathrm{~S}}^{*}=0.5996 \mathrm{~nm}$, можно оценить относительное содержание $\mathrm{Ag}_{2} \mathrm{~S}$ и $\mathrm{Ag}$ в твердом растворе замещения как $z=\left(a_{\mathrm{ss}}-a_{\mathrm{PbS}}\right) /\left(a_{\mathrm{Ag}_{2} \mathrm{~S}}^{*}-a_{\mathrm{PbS}}\right)$ и $x_{\mathrm{Ag}}=2 z$.

Согласно оценкам, сделанным с помощью минимизации рентгенограмм, с одной стороны, и по изменению периода решетки, с другой стороны, синтезированные твердые растворы $\mathrm{Ag}_{x} \mathrm{~Pb}_{1-x} \mathrm{~S}$ имеют состав $\sim \mathrm{Ag}_{0.05} \mathrm{~Pb}_{0.95} \mathrm{~S}, \sim \mathrm{Ag}_{0.08} \mathrm{~Pb}_{0.92} \mathrm{~S}, \sim \mathrm{Ag}_{0.10} \mathrm{~Pb}_{0.90} \mathrm{~S}$, $\sim \mathrm{Ag}_{0.12} \mathrm{~Pb}_{0.88} \mathrm{~S}$ и $\sim \mathrm{Ag}_{0.15} \mathrm{~Pb}_{0.85} \mathrm{~S}$, т. е. относительное содержание серы в них немного меньше 1.

Элементный анализ твердых растворов $\mathrm{Ag}_{x} \mathrm{~Pb}_{1-x} \mathrm{~S}$ был выполнен с помощью рентгеновского энергодисперсионного анализа EDX. Как пример на рис. 2 показаны EDX спектры сульфида свинца $\mathrm{PbS}$ и твердых растворов $\mathrm{Ag}_{0.08} \mathrm{~Pb}_{0.92} \mathrm{~S}$ и $\mathrm{Ag}_{0.12} \mathrm{~Pb}_{0.88} \mathrm{~S}$. В EDX спектре сульфида серебра (рис. 2,a) присутствуют только линии свинца и серы и слабая линия примесного кислорода в области $0.5 \mathrm{eV}$. Содержание $\mathrm{Pb}$ и $\mathrm{S}$ в порошке сульфида свинца равно $86.2 \pm 0.4$ и $13.2 \pm 0.5$ wt.\% и соответствует сульфиду $\sim \mathrm{PbS}_{0.99}$. В спектрах твердых растворов наряду с линиями $\mathrm{Pb}$ и $\mathrm{S}$ наблюдаются линии серебра $\mathrm{Ag}$ в области около $\sim 2.9 \mathrm{eV}$ (рис. 2, $b, c$ ). Содержание $\mathrm{Ag}, \mathrm{Pb}$ и $\mathrm{S}$ в твердых растворах $\sim \mathrm{Ag}_{0.08} \mathrm{~Pb}_{0.92} \mathrm{~S}$ и $\sim \mathrm{Ag}_{0.12} \mathrm{~Pb}_{0.88} \mathrm{~S}$ по данным EDX-анализа равно $3.6 \pm 0.2,82.1 \pm 0.4$, $12.9 \pm 0.5$ wt. $\%$ и $5.9 \pm 0.2,80.0 \pm 0.4,13.1 \pm 0.5$ wt. $\%$ соответственно и качественно согласуется с оценками относительного содержания $\mathrm{Ag}$ и $\mathrm{Pb}$ в твердых растворах по периоду решетки и путем минимизации рентгенограмм. Относительное содержание серы немного меньше стехиометрического и составляет $\sim 0.93-0.94$.

Линейный коэффициент термического расширения $\alpha_{\text {aver }}$ определяли как средний коэффициент в темпера- 

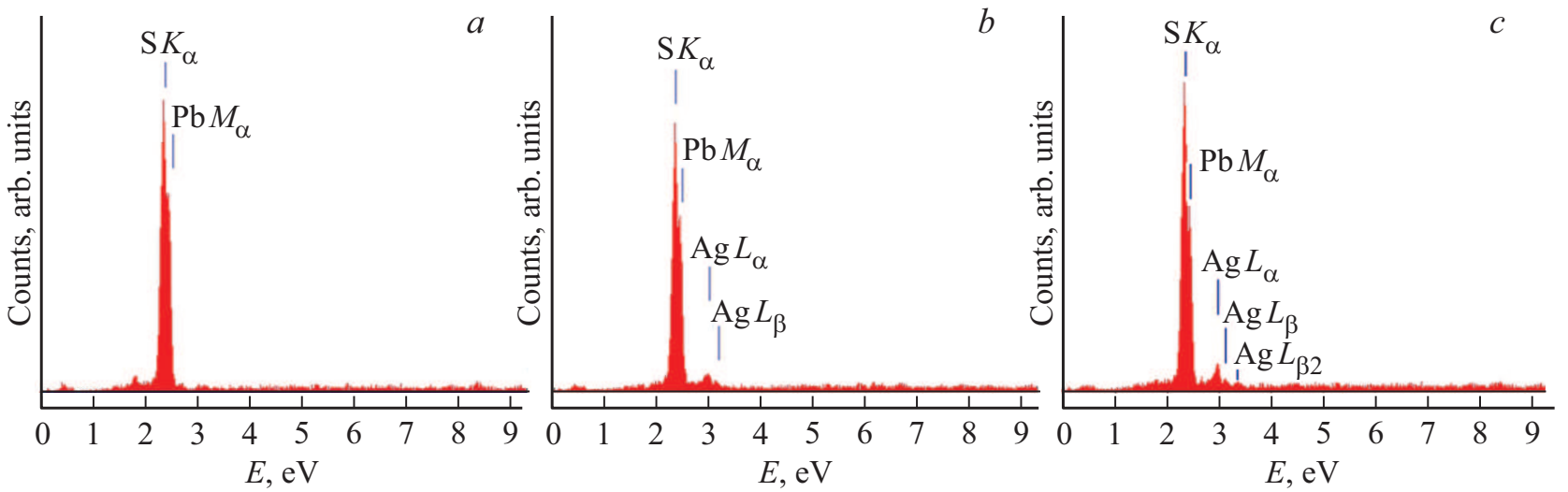

Рис. 2. Элементный $\mathrm{EDX}$ анализ порошков $\mathrm{PbS}(a), \sim \mathrm{Ag}_{0.08} \mathrm{~Pb}_{0.92} \mathrm{~S}(b)$ и $\sim \mathrm{Ag}_{0.12} \mathrm{~Pb}_{0.88} \mathrm{~S}(c)$.

турном интервале между начальной температурой $293 \mathrm{~K}$ и температурой измерения $T$

$$
\alpha_{\text {aver }}(T)=\frac{\Delta L}{L_{293 \mathrm{~K}} \Delta T}=\frac{L(T)-L_{293 \mathrm{~K}}}{L_{293 \mathrm{~K}}(T-293)},
$$

где $L(T), L_{293 \mathrm{~K}}$ - длина образца при температуре $T$ и при начальной температуре $293 \mathrm{~K}$.

Температурные зависимости среднего линейного коэффициента термического расширения $\alpha_{\text {aver }}(T)$ образцов $\mathrm{PbS}, \mathrm{Ag}_{2} \mathrm{~S}$ и твердых растворов $\mathrm{Ag}_{x} \mathrm{~Pb}_{1-x} \mathrm{~S}$ показаны на рис. 3. На зависимости $\alpha_{\text {aver }}(T)$ сульфида серебра в области температур $455-485 \mathrm{~K}$ наблюдается скачкообразное увеличение коэффициента термического расширения, обусловленное фазовым переходом „акантит

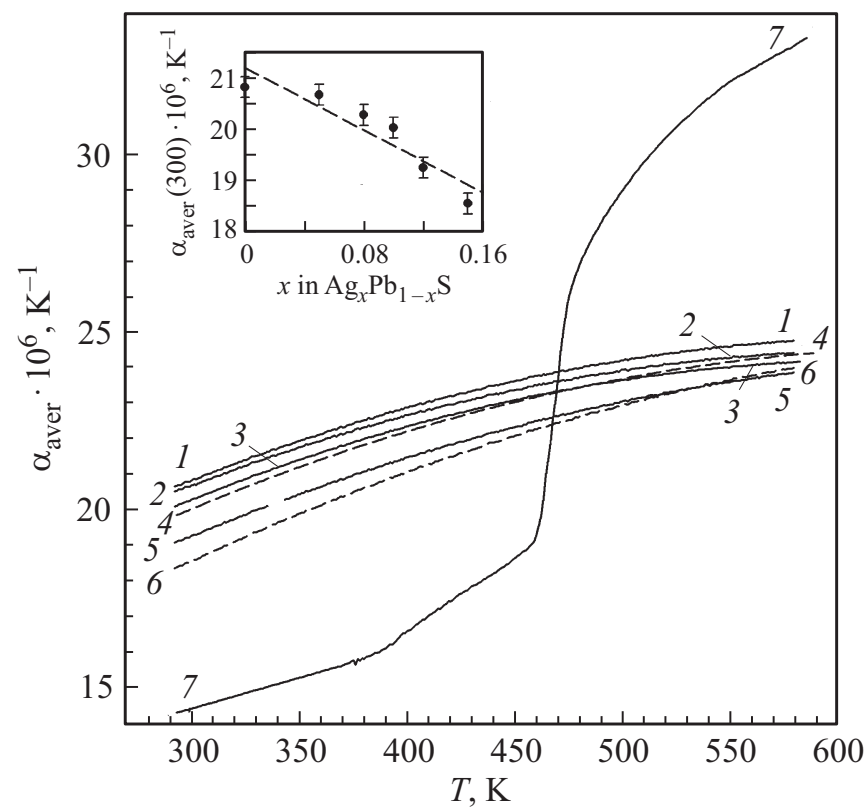

Рис. 3. Температурные зависимости среднего линейного коэффициента термического расширения $\alpha_{\text {aver }}(T)$ образцов $\mathrm{PbS}, \quad \mathrm{Ag}_{2} \mathrm{~S}$ и твердых растворов $\mathrm{Ag}_{x} \mathrm{~Pb}_{1-x} \mathrm{~S}: 1-\mathrm{PbS}$, $2-\mathrm{Ag}_{0.05} \mathrm{~Pb}_{0.95} \mathrm{~S}, 3-\mathrm{Ag}_{0.08} \mathrm{~Pb}_{0.92} \mathrm{~S}, 4-\mathrm{Ag}_{0.10} \mathrm{~Pb}_{0.90} \mathrm{~S}, 5-$ $\mathrm{Ag}_{0.12} \mathrm{~Pb}_{0.88} \mathrm{~S}, 6-\mathrm{Ag}_{0.15} \mathrm{~Pb}_{0.85} \mathrm{~S}, 7-\mathrm{Ag}_{2} \mathrm{~S}$. На вставке показано изменение $\alpha_{\text {aver }}$ при $300 \mathrm{~K}$ от состава твердых растворов.
$\alpha-\mathrm{Ag}_{2} \mathrm{~S}-\beta-\mathrm{Ag}_{2} \mathrm{~S}$ аргентит“. Ранее аналогичный скачок $\alpha_{\text {aver }}$ сульфида серебра наблюдали в работе [15]. Замещение атомов свинца атомами серебра в твердых растворах приводит к небольшому уменьшению коэффициентов термического расширения (рис. 3, вставка). Коэффициенты термического расширения $\alpha_{\text {aver }}(T)$ сульфида $\mathrm{PbS}$ и твердых растворов $\mathrm{Ag}_{x} \mathrm{~Pb}_{1-x} \mathrm{~S}$ в изученной области температур слабо увеличиваются с ростом $T$. Немного больший температурный рост $\alpha_{\text {aver }}$ наблюдается для твердого раствора $\mathrm{Ag}_{0.15} \mathrm{~Pb}_{0.85} \mathrm{~S}$, содержащего примесь сульфида серебра. В изученной области температур зависимости $\alpha_{\text {aver }}(T)$ сульфида свинца $\mathrm{PbS}$ и твердых растворов $\mathrm{Ag}_{x} \mathrm{~Pb}_{1-x} \mathrm{~S}$ можно аппроксимировать полиномами второго порядка.

$$
\begin{array}{ll} 
& \alpha_{\text {aver }}(T)=10.461 \cdot 10^{-6} \\
& +4.529 \cdot 10^{-8} T-3.545 \cdot 10^{-11} T^{2}\left(\mathrm{~K}^{-1}\right), \\
\mathrm{Ag}_{0.05} \mathrm{~Pb}_{0.95} \mathrm{~S}: & \alpha_{\text {aver }}(T)=10.525 \cdot 10^{-6} \\
& +4.458 \cdot 10^{-8} T-3.544 \cdot 10^{-11} T^{2}\left(\mathrm{~K}^{-1}\right), \\
\mathrm{Ag}_{0.08} \mathrm{~Pb}_{0.92} \mathrm{~S}: & \alpha_{\text {aver }}(T)=9.588 \cdot 10^{-6} \\
& +4.705 \cdot 10^{-8} T-3.769 \cdot 10^{-11} T^{2}\left(\mathrm{~K}^{-1}\right), \\
\mathrm{Ag}_{0.10} \mathrm{~Pb}_{0.90} \mathrm{~S}: & \alpha_{\text {aver }}(T)=9.282 \cdot 10^{-6} \\
& +4.641 \cdot 10^{-8} T-3.505 \cdot 10^{-11} T^{2}\left(\mathrm{~K}^{-1}\right), \\
\mathrm{Ag}_{0.12} \mathrm{~Pb}_{0.88} \mathrm{~S}: & \alpha_{\text {aver }}(T)=8.935 \cdot 10^{-6} \\
& +4.383 \cdot 10^{-8} T-3.106 \cdot 10^{-11} T^{2}\left(\mathrm{~K}^{-1}\right), \\
\mathrm{Ag}_{0.15} \mathrm{~Pb}_{0.85} \mathrm{~S}: & \alpha_{\text {aver }}(T)=7.328 \cdot 10^{-6} \\
& +4.685 \cdot 10^{-8} T-3.107 \cdot 10^{-11} T^{2}\left(\mathrm{~K}^{-1}\right) .
\end{array}
$$

Тепловое расширение твердого тела обусловлено ангармонизмом атомных колебаний. Для качественного описания теплового расширения в первом приближении потенциальную энергию $U(r)$ системы взаимодействующих атомов как функцию смещений $u=\left(r-r_{0}\right)$ записывают [21] в виде

$$
U(u)=A_{h} u^{2} / 2-\beta u^{3} / 3,
$$

где $A_{h}=\left(\partial^{2} U / \partial r^{2}\right)_{r=r_{0}}$ - постоянная, учитывающая вклад гармонических колебаний в потенциальную энер- 
гию, $\beta=\frac{1}{2}\left(\partial^{3} U / \partial r^{3}\right)_{r=r_{0}}$ - коэффициент ангармонизма атомных колебаний. С учетом распределения Больцмана среднее по времени отклонение $\langle u\rangle$ атома от положения равновесия определяется $[21,22]$ как

$$
\langle u\rangle=k_{\mathrm{B}} T \beta / A_{h}^{2},
$$

a линейный коэффициент термического расширения имеет вид

$$
\alpha(T)=\left(1 / a_{293 \mathrm{~K}}\right) d\langle u\rangle / d T=k_{\mathrm{B}} \beta /\left(A_{h}^{2} a_{293 \mathrm{~K}}\right) .
$$

Тепловое расширение (или сжатие) твердого тела можно объяснить только при учете ангармонизма атомных колебаний, т.е. при $\beta \neq 0$, так как в гармоническом приближении, когда $\beta=0$, коэффициент $\alpha=0$ и тепловое расширение отсутствует. Из (4) ясно, что наблюдаемое уменьшение коэффициента термического расширения при замещении атомов $\mathrm{Pb}$ атомами $\mathrm{Ag}$ в твердых растворах $\mathrm{Ag}_{x} \mathrm{~Pb}_{1-x} \mathrm{~S}$ может быть обусловлено ростом периода решетки, с одной стороны, и уменьшением ангармонизма атомных колебаний, с другой стороны. Действительно, при увеличении $x$ от 0 до 0.15 период $a_{B 1}$ твердых растворов вырос от 0.59320 до $0.59367 \mathrm{~nm}$, однако такое увеличение периода недостаточно для уменьшения $\alpha_{\text {aver }}(300)$ от $20.84 \cdot 10^{-6}$ до $18.57 \cdot 10^{-6} \mathrm{~K}^{-1}$. Если коэффициент $A_{h}$ при замещении свинца серебром остается постоянным, то наблюдаемое с ростом $x$ снижение $\alpha_{\text {aver }}$ твердых растворов $\mathrm{Ag}_{x} \mathrm{~Pb}_{1-x} \mathrm{~S}$ обусловлено, в основном, уменьшением ангармонизма колебаний атомов. Косвенным подтверждением уменьшением ангармонизма могут служить данные [8] по спектрам комбинационного рассеяния (КР) пленок $\mathrm{Ag}_{x} \mathrm{~Pb}_{1-x} \mathrm{~S}_{1-\delta}$. Согласно этим данным, пики 133 и $425 \mathrm{~cm}^{-1}$, присутствующие в спектре КР сульфида свинца и отвечающие за колебания связей металл-сера, при увеличении содержания в твердых растворах более легких атомов серебра постепенно смещаются в высокочастотную область до 145 и $440 \mathrm{~cm}^{-1}$ соответственно.

\section{4. Заключение}

Методом гидрохимического соосаждения из растворов ацетата свинца и нитрата серебра синтезированы порошки твердых растворов $\mathrm{Ag}_{x} \mathrm{~Pb}_{1-x} \mathrm{~S}$ с максимальным относительным содержанием серебра до $x=0.12$, имеющие кубическую структуру типа $B 1$. При большем содержании серебра в порошках появляется примесная фаза моноклинного сульфида серебра.

Установлено, что замещение свинца серебром в ограниченных твердых растворах $\operatorname{Ag}_{x} \mathrm{~Pb}_{1-x} \mathrm{~S}(x \leq 0.15)$ сопровождается небольшим ростом периода кубической решетки и небольшим снижением коэффициента термического расширения твердых растворов, которое обусловлено уменьшением ангармонизма атомных колебаний.

Автор благодарит Д.А. Ягодина за помощь в дилатометрических измерениях.

\section{Список литературы}

[1] R.B. Schoolar, J.R. Dixon. Phys. Rev. 137, 2A, 667 (1965).

[2] J.N. Zemmel, J.D. Jensen, R.B. Schoolar. Phys. Rev. 140, 1A, 330 (1965).

[3] С.И. Садовников, А.И. Гусев, А.А. Ремпель. Успехи химии 85, 7, 731 (2016).

[4] P. Junod. Helv. Phys. Acta 32, 6-7, 567 (1959).

[5] P. Junod, H. Hediger, B. Kilchör, J. Wullschleger. Phil. Mag. 36, 4, 941 (1977).

[6] S.I. Sadovnikov, A.I. Gusev. J. Mater. Chem. A 5, 34, 17676 (2017).

[7] С.И. Садовников, А.А. Ремпель, А.И. Гусев. Успехи химии 87, 4, 303 (2018)

[8] Л.Н. Маскаева, В.Ф. Марков, Т.В. Виноградова, А.А. Ремпель, А И. Гусев. Поверхность. Рентг., синхр. нейтр. исслед. 9, 35 (2003).

[9] С.И. Новикова, Н.Х. Абрикосов. ФТТ 5, 7, 1913 (1963).

[10] Yi Zhang, X. Ke, C. Chen, J. Yang, P.R.C. Kent. Phys. Rev. B 80, 2, 024304 (2009).

[11] С.И. Садовников, А.А. Ремпель. ФТТ 51, 11, 2237 (2009).

[12] S.I. Sadovnikov, N.S. Kozhevnikova, A.A. Rempel, A. Magerl. Thin Solid Films 548, 230 (2013).

[13] H. Okazaki, A. Takano. Ztsch. Naturforsch. A 40, 10, 986 (1985).

[14] А.И. Гусев, С.И. Садовников, А.В. Чукин, А.А. Ремпель. ФTT 58, 2, 246 (2016).

[15] S.I. Sadovnikov, A.I. Gusev, A.V. Chukin, A.A. Rempel. Phys. Chem. Chem. Phys. 18, 6, 4617 (2016).

[16] S.I. Sadovnikov, A.I. Gusev. J. Thermal Anal. Calorimetry 130, 2, 1155 (2018).

[17] Л.Е. Шелимова, В.Н. Томашик, В.И. Грицив. Диаграммы состояния в полупроводниковом материаловедении (системы на основе халькогенидов $\mathrm{Si}, \mathrm{Ge}, \mathrm{Sn}, \mathrm{Pb})$. Наука, М. (1991). $256 \mathrm{c}$.

[18] X'Pert HighScore Plus. Version 2.2e (2.2.5). (2009 PANalytical B.V. Almedo, the Netherlands.

[19] S.I. Sadovnikov, A.I. Gusev, A.A. Rempel. Superlat. Microstr. 83, 35 (2015).

[20] Ю.Ю. Лурье. Справочник по аналитической химии. Химия, М. (1987). 390 с.

[21] С.В. Вонсовский, М.И. Кацнельсон. Квантовая физика твердого тела. Наука, М. (1983). 336 с.

[22] N.W. Ashcroft, N.D. Mermin. Solid State Physics. Cornell University, N.Y.-Chicago-London (1976). 826 p.

Редактор Д.В. Жуманов 